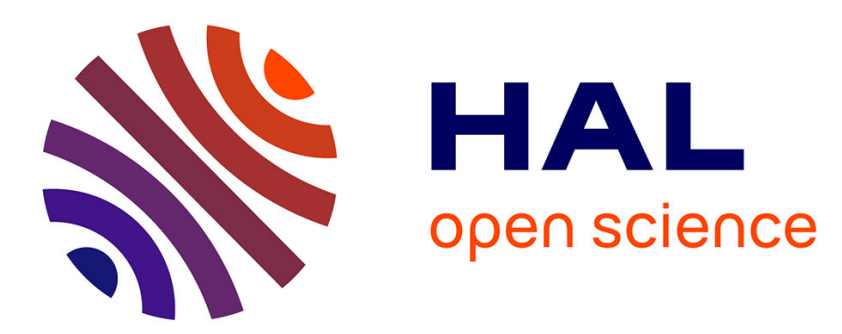

\title{
Analysis of disc brake temperature distribution during single braking under non-axisymmetric load
}

\author{
Adam Adamowicz, Piotr Grzes
}

\section{To cite this version:}

Adam Adamowicz, Piotr Grzes. Analysis of disc brake temperature distribution during single braking under non-axisymmetric load. Applied Thermal Engineering, 2011, 31 (6-7), pp.1003. 10.1016/j.applthermaleng.2010.12.016 . hal-00723969

\section{HAL Id: hal-00723969 \\ https://hal.science/hal-00723969}

Submitted on 16 Aug 2012

HAL is a multi-disciplinary open access archive for the deposit and dissemination of scientific research documents, whether they are published or not. The documents may come from teaching and research institutions in France or abroad, or from public or private research centers.
L'archive ouverte pluridisciplinaire HAL, est destinée au dépôt et à la diffusion de documents scientifiques de niveau recherche, publiés ou non, émanant des établissements d'enseignement et de recherche français ou étrangers, des laboratoires publics ou privés. 


\section{Accepted Manuscript}

Title: Analysis of disc brake temperature distribution during single braking under nonaxisymmetric load

Authors: Adam Adamowicz, Piotr Grzes

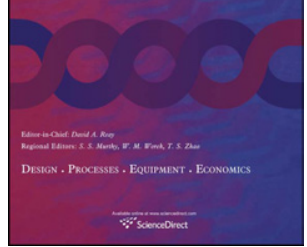

PII:

S1359-4311(10)00532-6

DOI:

10.1016/j.applthermaleng.2010.12.016

Reference: ATE 3340

To appear in: Applied Thermal Engineering

Received Date: 6 September 2010

Revised Date: 26 November 2010

Accepted Date: 6 December 2010

Please cite this article as: A. Adamowicz, P. Grzes. Analysis of disc brake temperature distribution during single braking under non-axisymmetric load, Applied Thermal Engineering (2010), doi: 10.1016/ j.applthermaleng.2010.12.016

This is a PDF file of an unedited manuscript that has been accepted for publication. As a service to our customers we are providing this early version of the manuscript. The manuscript will undergo copyediting, typesetting, and review of the resulting proof before it is published in its final form. Please note that during the production process errors may be discovered which could affect the content, and all legal disclaimers that apply to the journal pertain. 


\section{ANALYSIS OF DISC BRAKE TEMPERATURE DISTRIBUTION DURING SINGLE BRAKING UNDER NON-AXISYMMETRIC LOAD}

Adam Adamowicz, Piotr Grzes

Faculty of Mechanical Engineering, Bialystok University of Technology (BUT), 45C Wiejska Street, Bialystok, 15-351, Poland

Correspondence to: P. Grzes

e-mail: p.grzes@doktoranci.pb.edu.pl

phone number: (48) 08574693 12,

fax number: (48) 0857469210 . 


\begin{abstract}
This paper aims to study and compare the temperature distributions caused by mutual sliding of two members of the disc brake system basing on two- and three-dimensional FE modeling techniques and complexity of the phenomenon. First step of the analysis based on the previously developed model where the intensity of heat flux was assumed to be uniformly distributed on the friction surface of disc during braking process, and the heat is transferred exclusively in axial direction, whereas during the second, the three-dimensional rotor is subjected to the non-axisymmetric thermal load to simulate realistic thermal behaviour of the brake action. Operation conditions, thermo-physical properties of materials and dimensions of the brake system were adopted from the real representation of the braking process of the passenger vehicle. Arbitrarily selected four values of the velocities at the moment of brake engagement were applied to the models so as to investigate theirs influence on the obtained solutions of the temperature evolutions on the contact surface of the disc volume referring to two separated finite element analysis. The large amount of heat generated at the $\mathrm{pad} / \mathrm{disc}$ interface during emergency braking indisputably evokes non-uniform temperature distributions in the domain of the rotor, whereas the pad element is constantly heated during mutual sliding. The obtained results of the original code of three-dimensional modeling technique implemented to the conventional FE software revel high agreement with the solution of simplified process of friction heating.
\end{abstract}

Key words: Braking, Pad/disc system, Frictional heating, Moving heat source, Heat conduction, Finite element method. 
$c$ - specific heat, $\mathrm{J} / \mathrm{kgK}$;

[C] - heat capacity matrix;

$f$ - coefficient of friction;

$h$ - heat transfer coefficient, $W /\left(m^{2} K\right)$;

$k$ - thermal diffusivity, $\mathrm{m}^{2} / s$;

$K$ - thermal conductivity, $W /(m K)$;

[K] - conductivity matrix;

$p$ - pressure, $M P a$;

$p_{0}-$ contact pressure, $M P a ;$

$q$ - intensity of heat flux, $W / m^{2}$;

$r$ - inner radius, $m$;

$R$ - outer radius, $m$;

$\{\mathbf{R}\}$ - heat source vector;

$t$ - time, $s$;

$t_{s}$ - braking time, $s$;

$t_{s}^{0}-$ is the time of braking with constant deceleration, $s$;

$\Delta t$ - time step, $s$;

$T$ - temperature, ${ }^{\circ} \mathrm{C}$;

$T_{\infty}$ - ambient temperature, ${ }^{\circ} \mathrm{C}$;

$T_{0}$ - initial temperature, ${ }^{\circ} \mathrm{C}$;

$\{\mathbf{T}\}$ - temperature vector;

$V$ - velocity of the vehicle, $\mathrm{km} / \mathrm{h}$;

$V_{0}$ - initial velocity of the vehicle, $\mathrm{km} / \mathrm{h}$;

$\Delta x$ - the mesh size (smallest element dimension), $m$;

$z$ - axial coordinate, $m$;

Greek symbols

$\gamma$ - heat partition ratio;

$\delta$ - thickness 
$\varepsilon$ - coefficient of thermal activity

$\theta$ - circumferential coordinate, deg;

$\rho$ - density, $\mathrm{kg} / \mathrm{m}^{3}$;

$\phi_{0}$ - cover angle of pad, deg;

$\omega-$ angular velocity, $1 / s$;

$\omega_{0}$ - initial angular velocity, $1 / s$;

\section{Subscripts}

$d$ - indicates disc;

$p$ - indicates pad;

$w$ - indicates wheel; 


\section{INTRODUCTION}

The sliding contact of the members of disc brake results in kinetic energy conversion into heat at the pad/disc interface. The increase of friction moment is a limited quantity and depends on the coefficient of friction, radius of rubbing path, and forces that act on the pads. The process of slipping leads the increase of temperature, whereas its peak value is one of the most crucial factor in the course of action to occur. The temperature on the contact surfaces of the tribosystem during emergency braking intensified by significant thermal load due to frictional forces as well as the high velocity of the process is, in particular, important to predict in hazardous environments such as coal mines [1-4].

Complexity of the friction and wear processes state major difficulty of formulating universal physical model to determine critical operation conditions for specified case of braking action. Exact analytical solutions of temperature of friction pair may be obtained with restriction to semi-spaces, plane parallel strip or semi-planes. Typically the heat flux condition is applied at the region of contact. The three-dimensional temperature distributions of a moving heat source problem with a rectangular and elliptic source on a rectangular prism and circular source on a rotating cylinder was proposed in article [5]. The temperature and the thermal constriction resistance as a function of geometric characters and velocity were determined. The temperature and the thermal stresses of the pad (the strip) sliding with the constant retardation on a surface of the disc (the semi-space) both during heating and after the moment of standstill were studied [6]. However these geometric configurations may correlate with actual engineering applications, absence of the exact solutions, primarily application of finite areas of frictional heating systems should be noticed.

Rotating systems such as disc brakes in which pads cover solely the segment of rubbing path of a disc, are intrinsically submitted to non-axisymmetric thermal load. Simplifications of a real three-dimensional modelling techniques into two-dimensionality relating to the heat rate uniformly distributed in circumferential direction were so far accomplished [7-11]. In point of fact they enter simplifications of three-dimensional process of heating, which is omitted in systems where the friction surface of a body and counterbody is equal aircraft brakes and clutch systems [12]. Two models of heat dissipation utilizing axisymmetric arrangement of a disc brake: namely macroscopic and microscopic model were implemented in articles [7,8]. In the macroscopic model first law of thermodynamics has been taken into account and for microscopic model various characteristics such as braking time, velocity of the vehicle, thermo-physical properties of materials, contact pressure, and dimensions of a 
real disc brake assembly have been studied. Green's functions were used to determine temperature distributions in the disc and pad volume [8].

Formulation of the heat flux activity during frictional heating independent of circumferential coordinate $\theta$ may cause unrealistic contact conditions and falsify actual, elastic distortions. In order to simulate reasonable emergency braking process, the threedimensional FE model assuming nonlinear pressure distribution and angular velocity variability was proposed in article [13]. The thermo-physical properties of materials independent on temperature have been used.

Operation of disc brake above the certain range of the velocity may lead to thermoelastic distortions and in consequence to non-uniform pressure distribution due the interchanged moments of contact and its absence during rotation, known as thermoelastic instability (TEI) [14]. The upwind scheme in finite element formulation to prevent possible perturbations owing high Peclet number was developed [15].

The conventional finite element method is well adopted in stationary problems, however three-dimensional modelling of parts being in motion imposes very fine mesh due to high values of Peclet number, which determines the range of the velocity, above which oscillations may occur. The hybrid method combining the finite element method and the fast Fourier transform (FFT) technique, as an alternative approach in order to reduce computational time without loss of the temperature alterations owing the circumference of a disc brake was used $[3,4,9,10,15,16]$. The temperature distributions during different operation conditions were presented. The review of FEM-solutions of thermal problems of friction during braking are given in the article of Yevtushenko and Grzes [17].

In order to predict the temperature on the contact surfaces of elements of disc brake, experimental examinations including infrared techniques such as two colour pyrometry [18], infrared mapping $[3,4]$ as well as thermocouples $[1,19,20]$ were developed.

In this paper three-dimensional finite element analysis regarding movable behaviour of the disc brake system was developed and compared with the two-dimensional modelling of frictional heating problem derived from previous author's study [11]. In order to assure accuracy of the solution several finite element meshes of the two specified models of the real disc brake was tested. Investigation comprises dissimilar evolutions of the external load during mountain descent with constant velocity and application of single, emergency braking to standstill. For the purpose of comparison of obtained results, dimensions of the disc brake, operation conditions and thermo-physical material properties were adopted from the study developed previously [8]. Special concern is focused on the description of the FE modelling 
technique of the moving heat source problem corresponding to axial configuration of the same phenomenon.

\section{STATEMENT OF THE PROBLEM}

The disc brake system comprises in the majority two elements: rotating axisymmetric disc and immovable non-axisymmetric pad (Fig. 1). When the braking process occurs, the hydraulic pressure forces the piston and therefore pads and disc brake are in sliding contact. The friction at pad/disc interface resists the movement and the vehicle slows down, remain at the same level of the velocity during mountain descents or eventually, stops. The friction between disc and pads always opposes motion and the heat is generated due to conversion of the kinetic energy, whose portion is dissipated by convection to the atmosphere in accordance to Newton's law. However radiation as a third type of heat exchange always takes place, owing its negligibly amount is omitted in the modelling of the presented phenomenon.

In this paper non-axisymmetric thermal load due to the frictional heat generated during the single braking process implemented in the three-dimensional model is investigated to compare obtained solution of the temperature evolution on the disc friction surface with the two-dimensional representation of the constant heating studied previously [19] and to answer if there is the accurate range of the velocity under which the uniform heat flux ratio upon the circumference of the disc may results in the satisfactory outcomes. Thus primarily relevant in the present study was to examine proposed technique of moving heat source modelling problem. The solid disc brake was analyzed, where the dimensions, operating parameters and properties of materials were adopted from the study of Talati and Jalalifar [8].

For both types of disc models it has been assumed as follows:

1) material properties are isotropic and independent of the temperature;

2) the nominal surface of contact between the disc brake and the pad in operation is equal to the apparent surface in the sliding motion. The contact pressure is uniformly distributed over all friction surfaces hence the heat generation of the midplane is considered as symmetric;

3) the average of the intensity of heat flux into disc on the contact area equals [21]:

$$
\begin{gathered}
\left.q_{d}(r, \theta, t)\right|_{z=\delta_{d}}=(1-\gamma) \operatorname{fpr} \omega(t), r_{p} \leq r \leq R_{p}, 0 \leq \theta \leq 2 \pi, 0 \leq t \leq t_{s}, \\
\left.q_{p}(r, \theta, t)\right|_{z=\delta_{p}}=\gamma f p r \omega(t), r_{p} \leq r \leq R_{p}, 0 \leq \theta \leq \phi_{0}, 0 \leq t \leq t_{s},
\end{gathered}
$$


4) the heat partitioning factor representing the fraction of frictional heat flux entering the pad has the following form [22]

$$
\gamma=\frac{1}{1+\varepsilon}
$$

where

$$
\mathcal{E}=\frac{K_{d} \sqrt{k_{p}}}{K_{p} \sqrt{k_{d}}},
$$

is the thermal activity coefficient [23]

5) the frictional heat due to Newton's law has been dissipated to atmosphere on the other surfaces. The heat transfer coefficient $h$ is constant during simulation of braking process;

6) radiation is neglected by virtue of short braking time and hence relatively low temperature;

7) the wear on the contact surface is negligible.

In the three-dimensional model of solid disc, single surface of its symmetry in axial direction is insulated owing nature of considered phenomenon of heating. On both, the external, internal surface of the disc and contact surface free from friction, the convection conditions are prescribed due to the Newton's law of cooling. In the zone of temporary contact of the pad and disc, the thermal flux is assigned, which differs in the area of disc at any instant of braking time corresponding to the components of the intensity of heat flux product Eq. (2). The contact pressure $p_{0}$ is constant during the analysis, whereas the velocity for the first case of the analysis decreases linearly with time

$$
\omega(t)=\omega_{0}\left(1-\frac{t}{t_{s}^{0}}\right), 0 \leq t \leq t_{s}^{0},
$$

and during the second constant value of the velocity is assumed.

\section{MATHEMATICAL MODEL}

In order to determine the temperature distributions, both analytical and numerical techniques have been employed. The starting point of the analysis of the temperature fields in the disc volume, is the parabolic heat conduction equation given in the cylindrical coordinate system $(r, \theta, z)[24]$ 


$$
\frac{\partial^{2} T}{\partial r^{2}}+\frac{1}{r} \frac{\partial T}{\partial r}+\frac{1}{r^{2}} \frac{\partial^{2} T}{\partial \theta^{2}}+\frac{\partial^{2} T}{\partial z^{2}}=\frac{1}{k_{d}}\left(\frac{\partial T}{\partial t}+\omega \frac{\partial T}{\partial \theta}\right), r_{d} \leq r \leq R_{d}, 0 \leq \theta \leq 2 \pi, 0<z<\delta_{d}, t>0
$$

The boundary and initial conditions of non-stationary problem are established as follows (Fig. 1)

$$
\begin{gathered}
\left.K_{d} \frac{\partial T}{\partial z}\right|_{z=0}=q_{d}(r, \theta, t), r_{p} \leq r \leq R_{p}, 0 \leq \theta \leq 2 \pi, 0 \leq t \leq t_{s}, \quad(\Gamma) \\
\left.K_{d} \frac{\partial T}{\partial z}\right|_{z=0}=h\left[T_{\infty}-T(r, \theta, t)\right], r_{d} \leq r \leq r_{p}, 0 \leq \theta \leq 2 \pi, t \geq 0, \quad\left(\Omega_{1}\right) \\
\left.K_{d} \frac{\partial T}{\partial r}\right|_{r=R_{d}}=h\left[T_{\infty}-T(\theta, z, t)\right], 0 \leq \theta \leq 2 \pi, 0 \leq z \leq \delta_{d}, t \geq 0, \quad\left(\Omega_{2}\right) \\
\left.K_{d} \frac{\partial T}{\partial r}\right|_{r=r_{d}}=-h\left[T_{\infty}-T(\theta, z, t)\right], 0 \leq \theta \leq 2 \pi, 0 \leq z \leq \delta_{d}, t \geq 0, \quad\left(\Omega_{3}\right) \\
\left.\quad \frac{\partial T}{\partial z}\right|_{z=\delta_{d}}=0, r_{d} \leq r \leq R_{d}, 0 \leq \theta \leq 2 \pi, t \geq 0, \quad\left(\Omega_{4}\right) \\
T(r, \theta, z, 0)=T_{0}, r_{d} \leq r \leq R_{d}, 0 \leq \theta \leq 2 \pi, 0 \leq z \leq \delta_{d}
\end{gathered}
$$

\section{FE FORMULATION}

The object of this section is to develop approximate time-stepping procedures for axisymmetric transient governing equations. Using Galerkin's approach the following matrix form of the Eq. (6) is formulated [25]

$$
[\mathbf{C}] \frac{d\{\mathbf{T}\}}{d t}+[\mathbf{K}]\{\mathbf{T}\}=\{\mathbf{R}\}
$$

In order to solve the ordinary differential equation (13) the Crank-Nicolson method was used. Based on the assumption that temperature $\{T\}_{t}$ and $\{T\}_{t+\Delta t}$ at time $t$ and $t+\Delta t$ respectively, the following relation is specified

$$
\frac{1}{\Delta t}\left[\{\mathbf{T}\}_{t+\Delta t}-\{\mathbf{T}\}_{t}\right]=(1-\beta)\left\{\frac{d \mathbf{T}}{d t}\right\}_{t}+\beta\left\{\frac{d \mathbf{T}}{d t}\right\}_{t+\Delta t}
$$

Substituting Eq. (14) to Eq. (13) we obtain the following implicit algebraic equation

$$
([\mathbf{C}]+\beta \Delta t[\mathbf{K}])\{\mathbf{T}\}_{t+\Delta t}=([\mathbf{C}]-(1-\beta)[\mathbf{K}] \Delta t)\{\mathbf{T}\}_{t}+(1-\beta) \Delta t\{\mathbf{R}\}_{t}+\beta \Delta t\{\mathbf{R}\}_{t+\Delta t}
$$

where $\beta$ is the factor which ranges from 0.5 to 1 and is given to determine an integration accuracy and stable scheme. 
The transient finite element analysis was developed using the MD Patran/MD Nastran software package $[26,27]$. The finite element mesh of the disc model chosen for the analysis is illustrated in Fig. 1. The accuracy of the solution was obtained by testing different grids of finite elements, all of which had its own global number of elements due to specific division in circumferential, radial, and axial direction. The investigated, individual grids at the initial phase of the computations consisted of the 180, 240, 360, 450, 540 elements in the circumference, $10,15,20,25,30$ in the radial direction of the rubbing path, and 3, 3, 4, 4, 5 elements in the axial direction, respectively. The calculations of transient temperature of the rotor were carried out for the braking process with constant deceleration from the initial velocity of $25 \mathrm{~km} / \mathrm{h}$. The mesh of the finite elements was selected due to the difference of the obtained peak values of temperature relating to the finest mesh (model with the 540 elements in the circumference). The FE model of disc employed for the transient analysis consisted of 43200 eight-node hexagonal elements - HEX8 (360 elements in the circumference and 4 in axial direction) and 33693 nodes was used in the thermal analysis. As the mesh should be capable to reproduce the rapid temperature variations in the immediate vicinity of the contact surface, the size of the finite element increased with the distance from the region of generated surface of friction. To avoid inaccurate or unstable results, a proper fixed time step associated with spatial mesh size is essential [26].

$$
\Delta t=\Delta x^{2} \frac{\rho_{d} c_{d}}{10 K_{d}}
$$

In order to simulate moving heat source problem in the process of emergency braking, avoiding inaccuracies and oscillations to occur due to Peclet number which in presented case markedly exceeds the critical value of $P e=2$, time-stepping procedure corresponding to the relative pad/disc location was developed. The known amount of the intensity of heat flux entering the disc at succeeding instants of time, determined from the product of radial distance from the axis of disc on the friction surface, the contact pressure, velocity of the vehicle with the rate of deceleration Eq. (5) and friction coefficient was implemented to the FE models and the problem was solved based on the programming technique implemented to the commercial FEM programme [26,27]. In consequence spatial scheme of heating issue was accomplished and time dependent boundary conditions due to rotating pad activity were established. At the beginning of the process, after the brake engagement the amount of heat Eq. (1) was applied to the selected finite elements of pad area of the three-dimensional model. At the next time step, smaller than computed from the Eq. (16), the corresponding motion of heat source (brake pad) was calculated and displaced to the adjacent elements according to mutual sliding 
direction of the members of braking system. This process was modelled by the function, which imitated the process of covering of elements of the model during relative motion of rotating disc and fixed pad. While elements near by the front of pad were partially coated, the elements for the pad were simultaneously uncovered. The process was repeated and the time of pad imaginary contact area with the constant number of elements during computations was successively longer compatibly to the rate of deceleration until standstill. In the case of braking with constant velocity, the time of heating phase of three-dimensional model equals $\phi_{0} / 2 \pi$ of time of one rotation, whereas cooling phase lasts longer due to angular dimension of pad element and equals $\left(1-\phi_{0} / 2 \pi\right)$ of time of one rotation of the wheel.

The thermal flux entering the disc acted in the shape of the intensity of heat flux applied to three-dimensional finite elements in the area of pad operation during braking. Instead of automatic mesh generation capabilities, the original programming of the built-in commends of finite element software covering the algorithm of moving heat source described above, to assure correctness of the boundary conditions prescribed to specific elements, in particular, on the contact surface of disc was developed.

\section{RESULTS AND DISCUSSION}

In this paper temperature distributions of the disc brake without pad have been investigated. The disc rotor is subjected to high non-axisymmetric thermal load which may lead to non-uniform pressure and temperature distributions. Therefore three-dimensional analysis facilitate to examine temperature alterations in the circumference and theirs influence on the area inside the disc. Both convection and conduction have been analyzed. Particularly conduction was considered to be the most important mode of heat transfer.

In order to validate proposed transient numerical analysis two different types of the FE models were investigated, namely two- and three-dimensional configuration [8]. The part of presented temperature evolutions for two-dimensional model (braking with the constant retardation from the velocity of $V_{0}=100 \mathrm{~km} / \mathrm{h}$ ) originates from previous author's study [11]. The transient solution was performed for four selected initial velocities and related durations of braking process with constant deceleration. For the case of braking with constant velocity, exclusively the action of $V=100 \mathrm{~km} / \mathrm{h}\left(t_{s}=3.96 \mathrm{~s}\right)$ was tested. Material properties and operation conditions adopted in the analysis were the same for both types of FE models and are given in Tab. 1 and Tab. 2, respectively. 
In Fig. 2 numerical solutions of three-dimensional (continuous line) transient analysis of the disc contact surface temperature evolutions for specified radii of disc and position in the circumference $\theta=0^{\circ}$ confronted with the results obtained from the two-dimensional analysis (dashed line) are shown. In order to illustrate effect of frictionally excited heating over the friction surface, each of described figures covers four characteristic points of the position along the radius, namely the external radius of the disc $R_{d}$, the mean radius of rubbing path $r_{m}$, the minimal radius of pad $r_{p}$, and the internal radius of the disc $r_{d}$. The temperature curves directly correspond with the divers representations of the disc brake model configurations. It is noticeable, that the value of temperature in each case of axisymmetric heating of disc rapidly rises at the beginning of braking process, reaches its maximal value, then decreases to the lower level and eventually stops, which is coherent with the studies $[7,8,11,13]$. However fluctuations of temperatures have a presence in the solution of threedimensional model of frictional heating, the approximated values remain the approximate confirming the stability of the FE modelling in the two-dimensionality. The temperature curves expose saw-shaped character, which stems from the mutual rotational motion of the disc over the fixed pad [13,20]. The presented temperature evolution is obtained for certain, fixed spot on the circumference of a disc, therefore periods of heating and cooling phases may be distinguished. When the specific finite element of temperature calculations on the contact surface of disc is covered by pad (heating phase) the increase of temperature is noticeable because of accumulation of the frictional heat,. On the contrary when the pad is out of considered spot on the rubbing path, the cooling conditions according to Newton's law are established and the temperature decreases. The each revolution of the wheel strictly corresponds to one cycle of heating and cooling state. It is evident, that the temperature distribution correlates intermediately to the intensity of heat flux entering the disc, whose value in the plane model linearly decreases with time until the standstill, whereas spatial representation accessorily complies non-continuous heating of disc over the circumference. In the solution of two-dimensional model the highest temperature $\mathrm{T}=227.94^{\circ} \mathrm{C}$ is reached at the radial position $r=113.5 \mathrm{~mm}$, after time $t=3.022 \mathrm{~s}$, whereas the highest temperature $\mathrm{T}=259.34^{\circ} \mathrm{C}$ of fully three-dimensional disc, occurs at the same radius $r=113.5 \mathrm{~mm}$ after time $t=2.688 \mathrm{~s}$. The discrepancy of temperatures is lower at the end of the process and equals $T=3.52^{\circ} \mathrm{C}$. At the radial location of $76.5 \mathrm{~mm}$ the highest temperature of two- and threedimensional $\mathrm{FE}$ model equals $\mathrm{T}=98.98^{\circ} \mathrm{C}$ and $\mathrm{T}=108.31^{\circ} \mathrm{C}$, respectively. Exclusively at the internal surface of disc $r=66 \mathrm{~mm}$ in both FE models the highest value of temperature 
( $\mathrm{T}=47.32^{\circ} \mathrm{C}$ and $\mathrm{T}=47.43^{\circ} \mathrm{C}$ ) is attained at the end of the braking process. The maximal temperature at the radii of $76.5,95$ and $113.5 \mathrm{~mm}$ of the 3 -D model occurs at the same time $t=2.688 \mathrm{~s}$, whereas identical radial positions of axisymmetric case gives the solutions of time equalled $t=3.362 \mathrm{~s}, t=3.098 \mathrm{~s}$ and $t=3.022 \mathrm{~s}$ respectively.

The temperature evolutions on the contact surface of disc conditioned by the obtained results of two types of braking process simulations from the initial velocity $V_{0}=75 \mathrm{~km} / \mathrm{h}$ are shown in Fig. 3. In the two-dimensional model the temperature curves of surface of friction continuously alter with time analogously as was during braking from $V_{0}=100 \mathrm{~km} / \mathrm{h}$ (Fig. 2). In the spatial model, the increase of temperature is noticeable after the moment without sliding contact at the specified location in the circumference $\theta=0^{\circ}$, then the maximal temperature is attained, and succeeding period of pad absence effects with its rapid descend. The nature of the repeated heating and cooling states (Fig. 2-5) indicates two types of temperature curves, the first, describing period of heating is the concave curve, the second part of one rotation of disc is described by the convex curve, which is caused by the extortion of frictionally generated heat impulse and its absence after the pad transition with the convective cooling. The time of these periods differs due to the velocity of braking and is constant at its specified value at each radial location on the friction surface. The temperature curves at the radii of $66,76.5 \mathrm{~mm}$ almost coincide near the time of full stop with both solutions owing complexity of the model, whereas the discrepancy of temperatures during the action and after standstill overlaps less at radii $r=95$ and $r=113.5 \mathrm{~mm}$.

In Fig. 4 temperature evolutions on the contact surface during braking from the initial velocity of $50 \mathrm{~km} / \mathrm{h}$ are presented. The similar pattern of temperature progress with regard to Fig. 2 and Fig. 3 may be observed. The averages of temperatures curves of 3D-model agree highly with the results obtained from the model drawn on the intensity of heat flux uniformly distributed in the circumference of the disc. The maximal temperature reached during barking from $50 \mathrm{~km} / \mathrm{h}$ equals $\mathrm{T}=81.86^{\circ} \mathrm{C}$ and $\mathrm{T}=112.54^{\circ} \mathrm{C}$ for two- and three-dimensional model respectively. The seventh rotation ends at the position of pad covering the tested location in the circumference $\theta=0^{\circ}$ (twenty eighth rotation in Fig. 2). Therefore the temperature after the full stop is closer to the value obtained in the axisymmetric problem of frictional heating. Relating to the radial location of the presented temperature curves, proportion of the distance from $\mathrm{z}$ axis is not equalled to the corresponding values of temperature. This phenomenon may be attributed to the contact surface of disc which is situated on its margin, thus the area beneath rubbing path absorb more heat during action and temperature is adequately lower. 
The evolutions of temperatures during braking from the lowest tested velocity $V_{0}=25 \mathrm{~km} / \mathrm{h}$ are shown in Fig. 5. It may be observed that only one rotation was accomplished within sliding process. The plotted curves at each radius reveal significant disagreement of the two presented solutions. The maximal value of temperature of threedimensional model attained in the action, at radius of $113.5 \mathrm{~mm}$ equals $T=64.73^{\circ} \mathrm{C}$, whereas in opposite approach of modelling, temperature equals $T=41.21{ }^{\circ} \mathrm{C}$. Such a spread of results, relating to the simplified process of heating may mislead the actual effect temperature variations. The moment, when the highest temperature occurs evidently depends on the investigated location in the circumference, and in particular case may be identical to the solution of two-dimensional model. At the radius of $66 \mathrm{~mm}$ the temperature remains unchanged in both cases.

Fig. 6 depicts the temperature fields on contact surface in the circumference at the moment of standstill for selected radial locations and different initial velocities: a) $V=100 \mathrm{~km} / \mathrm{h}$, b) $V=75 \mathrm{~km} / \mathrm{h}, \mathrm{c}) V=50 \mathrm{~km} / \mathrm{h}$, d) $V=25 \mathrm{~km} / \mathrm{h}$. The temperature curves of three-dimensional model are plotted with regard to the constant temperature of twodimensional FE model. In fact temperature distribution of axial model in Fig. 6 should be illustrated as a point, but to facilitate clarity straight line (dashed) is used. It may be observed that the temperature rises when the pad passes specified position on the friction surface of disc and decreases to the level beneath the distribution of two-dimensional event. The highest calculated range of amplitude of temperature occurs on the external edge of disc in each case of braking. For $r=76.5 \mathrm{~mm}$ the temperature is more smooth under pad transition, whereas on the edge of external surface is almost constant in the circumference because of the distance from the rubbing path. The presented plots of temperature drawn along the circumferential direction which correspond to the articles of Floquet and Dubourg [9] and Cho and Ahn [16].

The average temperature of spatial problem during braking from $V=25 \mathrm{~km} / \mathrm{h}$ (Fig. 6d) at the radius $r=113.5,95,76.5$ and $66 \mathrm{~mm}$ equals $T=35.59,33.47,25.74,20.09^{\circ} \mathrm{C}$ respectively, whereas temperature at the end of braking of 2D model equals $T=35.65,33.52$, 25.65, $20.13^{\circ} \mathrm{C}$, therefore when the initial angular velocity equals $\omega_{0}=22.116 \mathrm{~s}^{-1}\left(V_{0}=25 \mathrm{~km} / \mathrm{h}\right)$, the mean temperature coincides in each case of the solution with the relative error lower than $0.5 \%$, whereas for the initial velocity $\omega_{0}=44.232,66.348$, $88.464 \mathrm{~s}^{-1}\left(V_{0}=50,75,100 \mathrm{~km} / \mathrm{h}\right)$ equals 1,2 , and $3 \%$ (Fig. 6c,b,a), respectively. However this arithmetic mean of spatial distribution of temperature is not able to include realistic response of material heating of disc during process of braking. The level of temperature in 
each case of brake engagement owing different initial velocities corresponds to temperatures at the moment of standstill presented in Fig. 2-5. The temperature distributions expose importance of place under examination in the circumference of spatial model and its parallel time.

Fig. 7 shows the temperature distributions that evolved on the external radius of disc $(r=113.5 \mathrm{~mm})$ at different locations in depth during braking from the previously selected initial velocities of the vehicle: a) $V_{0}=100 \mathrm{~km} / \mathrm{h}$, b) $V_{0}=75 \mathrm{~km} / \mathrm{h}$, c) $V_{0}=50 \mathrm{~km} / \mathrm{h}$, d) $V_{0}=25 \mathrm{~km} / \mathrm{h}$. The solutions of spatial model are confronted with the axisymmetric representation. The permanent rise of temperature until attainment of its maximal value and slightly descend after, near the moment of full stop on the contact surface $(z=0 \mathrm{~mm})$ and for $z=1,2 \mathrm{~mm}$ is noticeable. The bigger distance $(z=3.5,5.5 \mathrm{~mm})$ results in constant increase of temperature until the end of the process. The character of evolution of temperature on the axial position $z=1,2 \mathrm{~mm}$ slightly differs from the trace at the position of $0 \mathrm{~mm}$, whereas temperature on the depth of $2,3.5,5.5 \mathrm{~mm}$ evolves almost identically to the curves generated in axisymmetric model. The presented evolutions of temperature are plotted for the specified location in the circumference, thus agreement of the results owing type of the frictionally excited heating process strongly depends on the position of testing as well. Nevertheless chosen point $\theta=0^{\circ}$ in the circumference of the three-dimensional model during braking from $V=100 \mathrm{~km} / \mathrm{h}$ (Fig. 7a) and $V=50 \mathrm{~km} / \mathrm{h}$ (Fig. 7c) almost overlapped selected axial distances from contact surface of two-dimensional model. It stems from the fact that during the immediate moment of standstill, pad covers the spot of disc under examination and therefore causes slight rise of temperature sufficient to improve agreement of plane and spatial solution of heating. It has to be noticed that in the two-dimensional model convective terms on the friction surface have been neglected and constant heating with the same value of thermal flux in the circumference during braking was established. All of the temperature curves in Fig. 7 which represents two-dimensional model on the depth of $z=2,3.5,5.5 \mathrm{~mm}$ exceed values of the related temperature evolutions of spatial model during braking process. However temporary peak values of temperature during pad passing are higher than smoothed evolution of temperature of uniform heating in the circumference, owing the average amount of temperature of spatial model its influence on heating is lowered. The temperature evolutions of braking from the angular velocity $\omega_{0}=22.116 \mathrm{~s}^{-1}$ (Fig. 7d) confirm that for that case the solutions of heat transfer in disc brake are obviously dissimilar when consider two- and threedimensional model. 
In Fig. 8 the temperature distribution on the contact surface along the radius of disc at four different moments of time braking time $t_{s}$ obtained during braking from the initial velocity $V_{0}=100 \mathrm{~km} / \mathrm{h}$ are shown. The circumferential location of presented temperature curves was chosen due to the disc/pad related position next to sliding pad. The temperature for the particular distances from the axis of the rotor correlates with presented curves plotted versus braking time for four characteristic radii Fig. 2. The value of temperature on the internal surface of disc coincides within both configuration of the model of frictional heating at any step of time. At the end of braking process, the temperature on the friction surface along the radius is approximate. Nevertheless for the time $t=25 \% t_{s}, 50 \% t_{s}$ and $75 \% t_{s}$ the temperature in the contact zone obtained from spatial model highly exceeds the corresponding values of the two-dimensional phenomenon, which stems from the fact that during braking with linear decrease of time the pad influences directly the level of temperature until the moment of full stop.

In Fig. 9 the temperature evolutions on the contact surface of disc versus time during braking with the constant velocity of $100 \mathrm{~km} / \mathrm{h}$ are illustrated. The temperature of the twodimensional solution at the position $r=76.5,95$, and $113.5 \mathrm{~mm}$ rapidly rises at the beginning of action, then linear increase is noticeable until standstill, whereas in case of spatial model the delay of temperature variations is may be seen at the beginning of braking, after which impulse nature of heating takes place. The process of heating relating to the average of temperature highly agrees within different FE model of the same phenomenon. The maximal value of temperature on the contact surface is reached at the external radius of disc at the end of braking for two-dimensional model $T=494.35^{\circ} \mathrm{C}$ and for the last pad rotation at the time of $t=3.906 \mathrm{~s}, T=526.63^{\circ} \mathrm{C}$. The similar approach of simulation of braking process with constant velocity using three-dimensional model has been investigated [2]. Assumptions regardless circumferential conductive flux were made with the assessment of the entered error.

The temperature variations at different locations in depth from the disc/pad interface $z=0 \mathrm{~mm}$ to the surface of symmetry of disc $z=5.5 \mathrm{~mm}$ are shown in Fig. 10. With a distinction to the case of braking with linearly decreased velocity of the vehicle (Fig. 7a) braking with the constant velocity results in the increase of temperature after the initial moment of time nearly linear until full stop. The temperatures of two-dimensional model at the position $z=-1,-2,-3.5,-5.5 \mathrm{~mm}$ are higher at any instant of braking time. 
The temperature distributions on the friction surface along the circumference of disc for the case of braking with constant velocity of $100 \mathrm{~km} / \mathrm{h}$ are shown in Fig. 11. It is clearly noticeable for $r=76.5,95,113.5 \mathrm{~mm}$ that the temperature on the contact surface corresponds to pad transition over the rotational disc.

Fig. 12 depicts the corresponding temperature distributions on the contact surface of disc brake for selected moments of time. The temperature profile for the time equalled 0.25 of $t_{s}$ has the longest linear section in the middle of braking path. At the subsequent moments of time this spot is more rounded. In the contrary to Fig. 8, this case of braking with constant velocity $V=100 \mathrm{~km} / \mathrm{h}$ lasting $3.96 \mathrm{~s}$ results in aligned respective plots of temperature fields due to the two- and three-dimensional description of the analyzed phenomenon.

\section{CONCLUSIONS}

In this paper three-dimensional finite element analysis was carried out for temperature distributions assessment in disc brake system during single braking. The disc rotor was examined without pad presence. The heat conductivity problem was divided into two cases of different configurations of the disc brake FE models owing complexity of the problem.

From the obtained results we can conclude, that the temperature of disc on the contact surface of two-dimensional model and averaged solution of spatial solution during braking with the constant deceleration sharply rises at the beginning of the process, reached its maximal value and eventually stops on the lower level, whereas if the velocity of the vehicle is constant the temperature after the initial moment of time increases approximately linearly.

The character of temperature evolution on the contact surface of disc and its influence in depth reveals high coincidence with regard to the three-dimensional model and simplified two-dimensional representation of the considered problem. Therefore validation of the outcomes of previously conducted study of frictional heating of disc with uniformly distributed heat flux has been made.

Fully three-dimensional analysis under non-axisymmetric thermal load provides information of realistic behaviour of temperature alterations distinguishing period of heating (concave curve) and cooling (convex curve) in the selected spot on the friction surface during both single braking to full stop and braking during mountain descent with the constant velocity. 
Based on the investigated individual cases of single braking from the different initial velocities, it may be observed that if the lower velocity is, the worse compatibility is obtained relating to two- and three-dimensional model. The above axisymmetric solution of the temperature fields of disc indicates that the solution is reliable if the angular velocity of disc exceeds $\omega_{0}=44.232 s^{-1}$.

The developed finite element analysis of friction heating of disc during emergency braking has confirmed the solution in the two-dimensionality feasible further to carry the fully transient simulation with the time dependent material properties and coefficient of friction due to adequately low computer storage requirements.

\section{References}

[1] Z.-C. Zhu, Y.-X. Peng, Z.-Y. Shia, and G.-A. Chen, Three-dimensional transient temperature field of brake shoe during hoist's emergency braking, Applied Thermal Engineering 29 (5-6) (2009) 932-937.

[2] L. Wawrzonek, R.A. Bialecki, Temperature in a disk brake, simulation and experimental verification, International Journal of Numerical Methods for Heat \& Fluid Flow 18 (3-4) (2008) 387-400.

[3] S. Scieszka, M. Zolnierz, The effect of the mine winder disc brake's design feature on its thermoelastic instability. Part I. Set-up for finite element modelling and numerical model verification, Problems of Machines Operation and Maintenance 42 (3) (2007) 111-124.

[4] S. Scieszka, M. Zolnierz, The effect of the mine winder disc brake's design feature on its thermoelastic instability. Part II. Finite element simulation, Problems of Machines Operation and Maintenance 42 (4) (2007) 183-193.

[5] N. Laraqi, A. Bairi, L. Segui, Temperature and thermal resistance in frictional devices, Applied Thermal Engineering 24 (17-18) (2004) 2567-2581.

[6] A. Yevtushenko, M. Kuciej, Temperature and thermal stresses in a pad/disc during braking, Applied Thermal Engineering 30 (4) (2010) 354-359.

[7] F. Talati, S. Jalalifar, Investigation of heat transfer phenomena in a ventilated disk brake rotor with straight radial rounded vanes, Journal of Applied Sciences 8 (20) (2008) 3583-3592.

[8] F. Talati, S. Jalalifar, Analysis of heat conduction in a disk brake system, Heat Mass Transfer 45 (2009) 1047-1059. 
[9] A. Floquet, M.-C. Dubourg, Non-axisymmetric effects for three-dimensional analysis of a brake, Trans. ASME, J. Tribol. 116 (1994) 401-408.

[10] A. Floquet, M.-C. Dubourg, Realistic braking operation simulation of ventilated disk brakes, ASME J. Tribol. 118 (1996) 466-472.

[11] P. Grzes, Finite element analysis of disc temperature during braking process, Acta mechanica et automatica 3 (4) (2009) 36-42.

[12] S. Zhaoa, G.E. Hilmas, L.R. Dharani, Behavior of a composite multidisk clutch subjected to mechanical and frictionally excited thermal load, Wear 264 (2008) 10591068.

[13] C.H. Gao, X.Z. Lin, Transient temperature field analysis of a brake in a nonaxisymmetric three-dimensional model, Journal of Materials Processing Technology 129 (2002) 513-517.

[14] Y.-B. Yi, J.R. Barber, P. Zagrodzki, Eigenvalue solution of thermoelastic instability problems using Fourier reduction, Proc. R. Soc. Lond. A 456 (2000) 2799-2821.

[15] Y.-B. Yi, J.R. Barber, D.L. Hartsock, Thermoelastic instabilities in automotive disc brakes - Finite element analysis and experimental verification. In: J.A.C.Martins and Manuel D. P. Monteiro Marques eds., Contact Mechanics, Kluwer, Dordrecht, (2002) 187-202.

[16] CH. Cho, S. Ahn, Transient thermoelastic analysis of disk brake using the fast Fourier transform and finite element method, Journal of Thermal Stresses 25 (2002) 215-243.

[17] A. Yevtushenko, P. Grzes, FEM-modeling of the frictional heating phenomenon in the pad/disc tribosystem (a review), Numerical Heat Transfer. Part A 58 (3) (2010) 207226.

[18] J. Thevenet, M. Siroux, B. Desmet, Measurements of brake disc surface temperature and emissivity by two-color pyrometry, Applied Thermal Engineering 30 (6-7) (2010) 753-759.

[19] M. Siroux, A.-L. Cristol-Bulthe, Y. Desplanques, B. Desmet, G. Degallaix, Thermal analysis of periodic sliding contact on a braking tribometer, Applied Thermal Engineering 28 (17-18) (2008) 2194-2202.

[20] H.S. Qi and A.J. Day, Investigation of disc/pad interface temperatures in friction braking, Wear 262 (2007) 505-513.

[21] F.F. Ling, Surface mechanics, John Wiley \& Sons, 1973 New York.

[22] H. Blok, Fundamental mechanical aspects in boundary lubrication, SAE Trans. 46 (1940) 54-68. 
[23] A.V. Luikov, Analytical heat diffusion theory, Academic Press, 1968 New York.

[24] W. Nowacki, Thermoelasticity, Pergamon Press, 1962 Oxford.

[25] R.W. Lewis, P. Nithiarasu, K.N. Seetharamu, Fundamentals of the finite element method for Heat and Fluid Flow, John Wiley \& Sons, 2004.

[26] MSC.Software, Reference Manual MD Nastran, Version r2.1, 2008.

[27] MSC.Software, Reference Manual MD Patran, Version r2.1, 2008.

\section{Figure Captions}

1. A schematic diagram with three-dimensional finite element mesh of a pad/disc brake system.

2. Evolutions of temperature on the contact surface of the disc brake during braking from the initial velocity $V_{0}=100 \mathrm{~km} / \mathrm{h}$ at selected radial locations for three- (solid curves) and twodimensional (dashed curves) models.

3. Evolutions of temperature on the contact surface of the disc brake during braking from the initial velocity $V_{0}=75 \mathrm{~km} / \mathrm{h}$ at selected radial locations for three- (solid curves) and twodimensional (dashed curves) models.

4. Evolutions of temperature on the contact surface of the disc brake during braking from the initial velocity $V_{0}=50 \mathrm{~km} / \mathrm{h}$ at selected radial locations for three- (solid curves) and twodimensional (dashed curves) models.

5. Evolutions of temperature on the contact surface of the disc brake during braking from the initial velocity $V_{0}=25 \mathrm{~km} / \mathrm{h}$ at selected radial locations for three- (solid curves) and twodimensional (dashed curves) models.

6. Temperature distributions on the contact surface at the moment of standstill of braking from the initial velocity: a) $V_{0}=100 \mathrm{~km} / \mathrm{h}$, b) $V_{0}=75 \mathrm{~km} / \mathrm{h}$, c) $V_{0}=50 \mathrm{~km} / \mathrm{h}$, d) $V_{0}=25 \mathrm{~km} / \mathrm{h}$ for three- (solid curves) and two-dimensional (dashed curves) models.

7. Evolutions of the disc temperature at different axial distances from the contact surface at the radius of $113.5 \mathrm{~mm}$ during braking from the initial velocity: a) $V_{0}=100 \mathrm{~km} / \mathrm{h}, \mathrm{b}$ ) $V_{0}=75 \mathrm{~km} / \mathrm{h}$, c) $V_{0}=50 \mathrm{~km} / \mathrm{h}$, d) $V_{0}=25 \mathrm{~km} / \mathrm{h}$ for three- (solid curves) and twodimensional (dashed curves) models. 
8. Temperature distributions on the friction surface versus radial direction during braking from the initial velocity $V_{0}=100 \mathrm{~km} / \mathrm{h}$ for three- (solid curves) and two-dimensional (dashed curves) models.

9. Evolutions of temperature on the contact surface of the disc brake during braking with constant velocity $V=100 \mathrm{~km} / \mathrm{h}$ at selected radial locations for the two- and threedimensional problem for three- (solid curves) and two-dimensional (dashed curves) models.

10. Evolutions of the disc temperature at different axial distances from the contact surface at the radius of $113.5 \mathrm{~mm}$ during braking with constant velocity $V=100 \mathrm{~km} / \mathrm{h}$ for three(solid curves) and two-dimensional (dashed curves) models.

11. Temperature distributions on the contact surface at the moment of standstill, process of braking with the constant velocity $V=100 \mathrm{~km} / \mathrm{h}$ for three- (solid curves) and twodimensional (dashed curves) models.

12. Temperature distributions on the friction surface versus radial direction during braking with the constant velocity $V=100 \mathrm{~km} / \mathrm{h}$ for three- (solid curves) and two-dimensional (dashed curves) models. 
- FEA enables to predict temperature variations in a real disc brake

- Mean temperatures on the contact surface correspond with results of 2D model

- Velocity affects advisability of use of two-dimensional FE modelling 


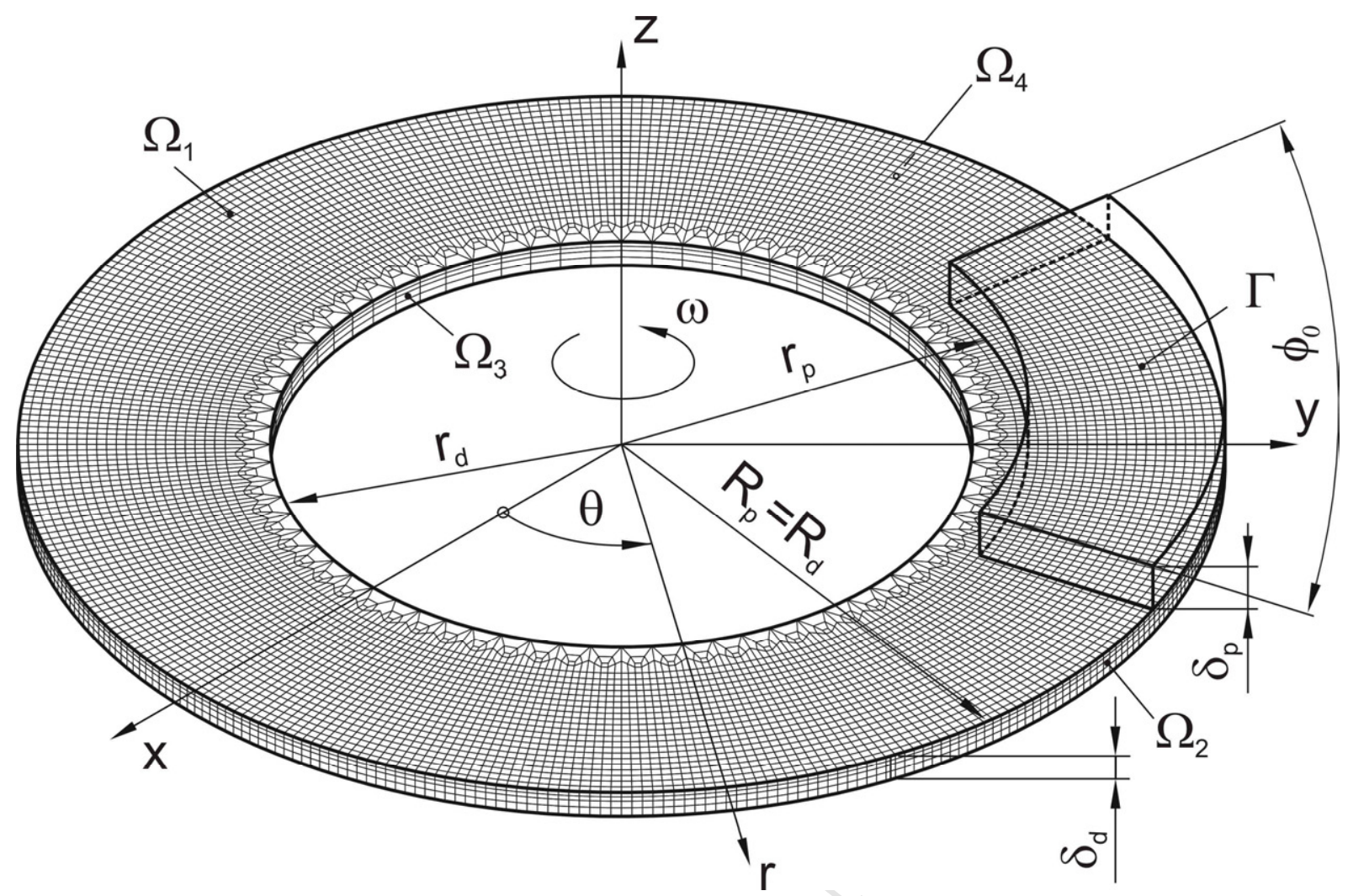

Fig. 1

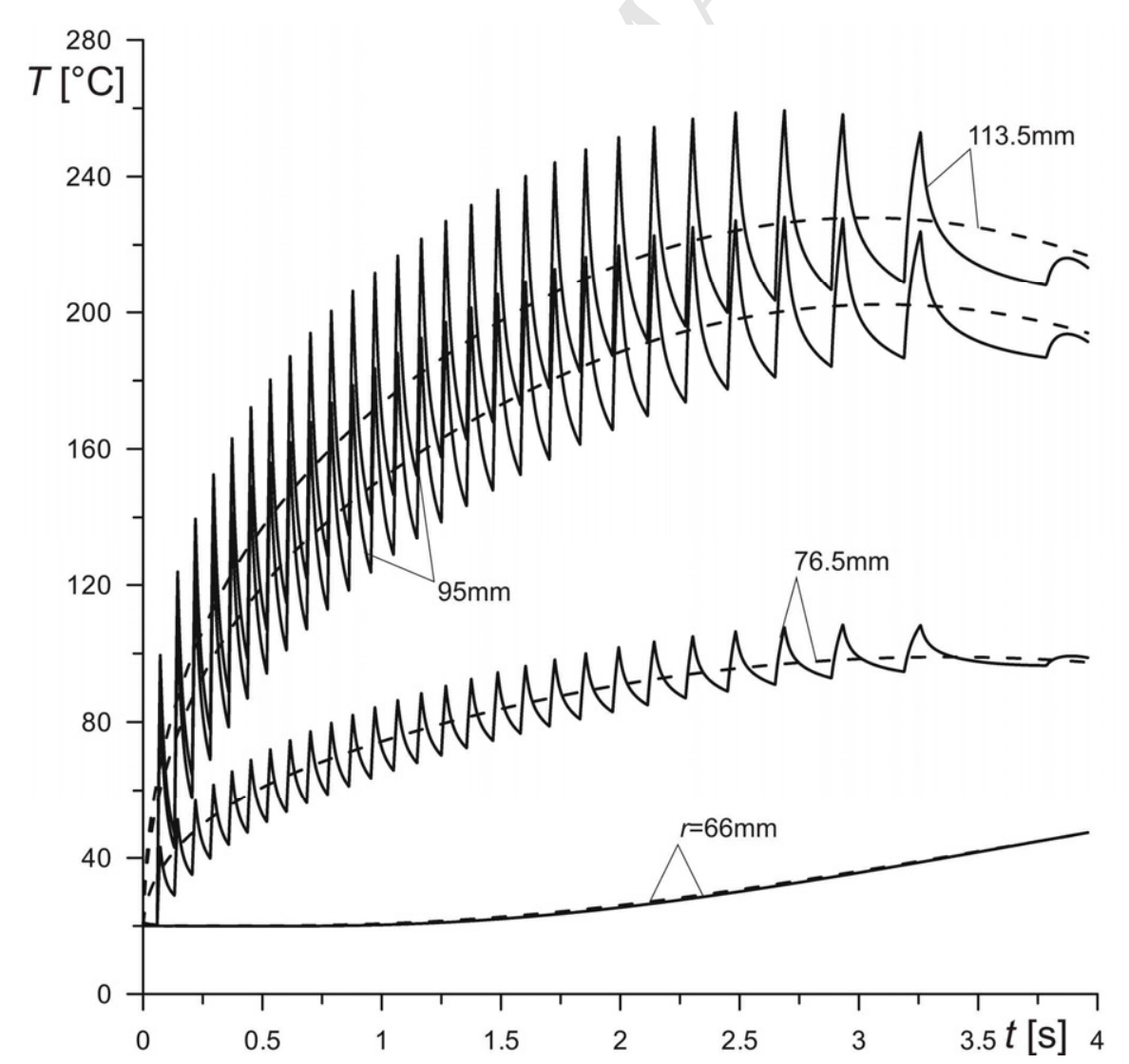

Fig. 2 


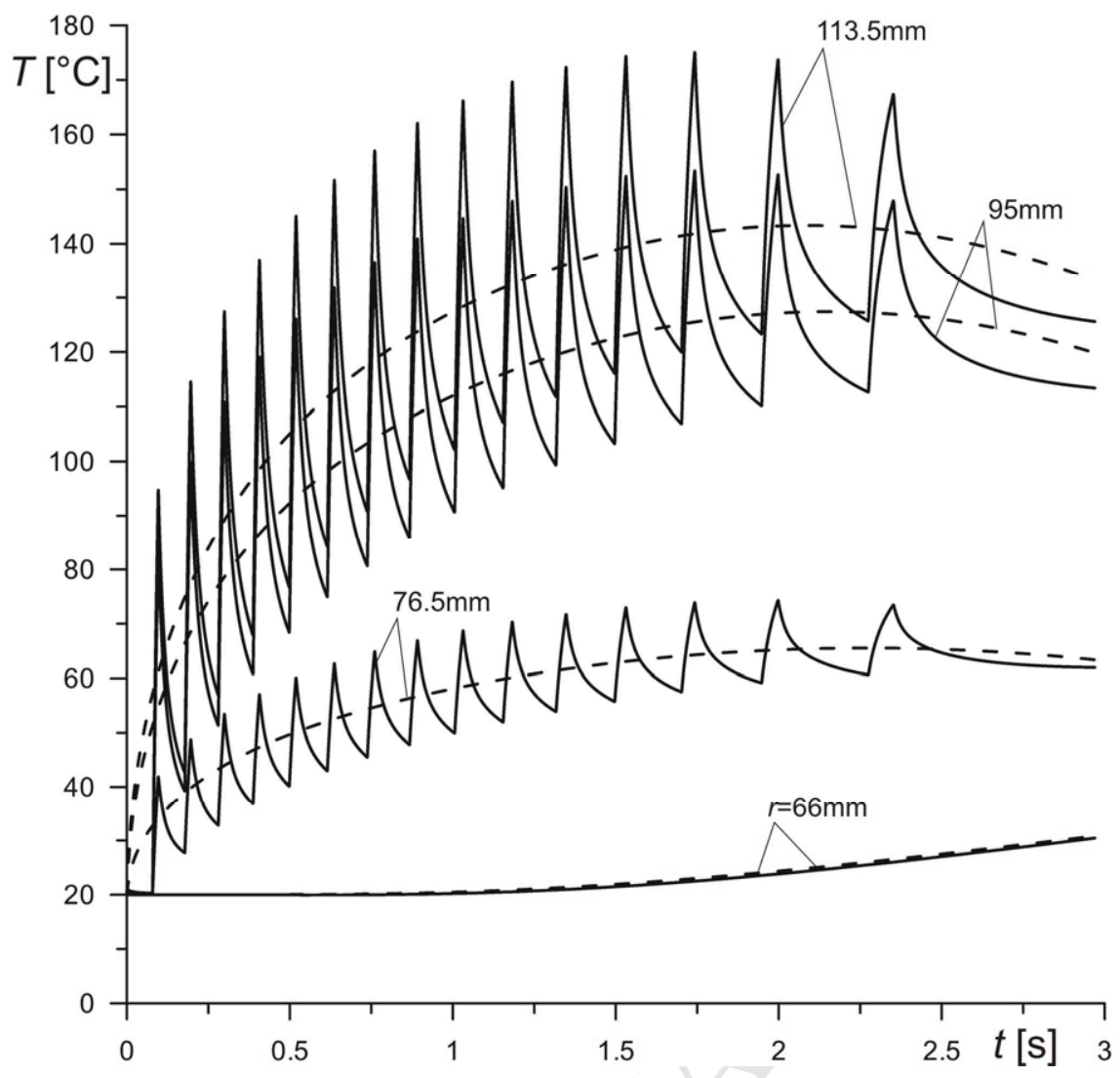

Fig. 3

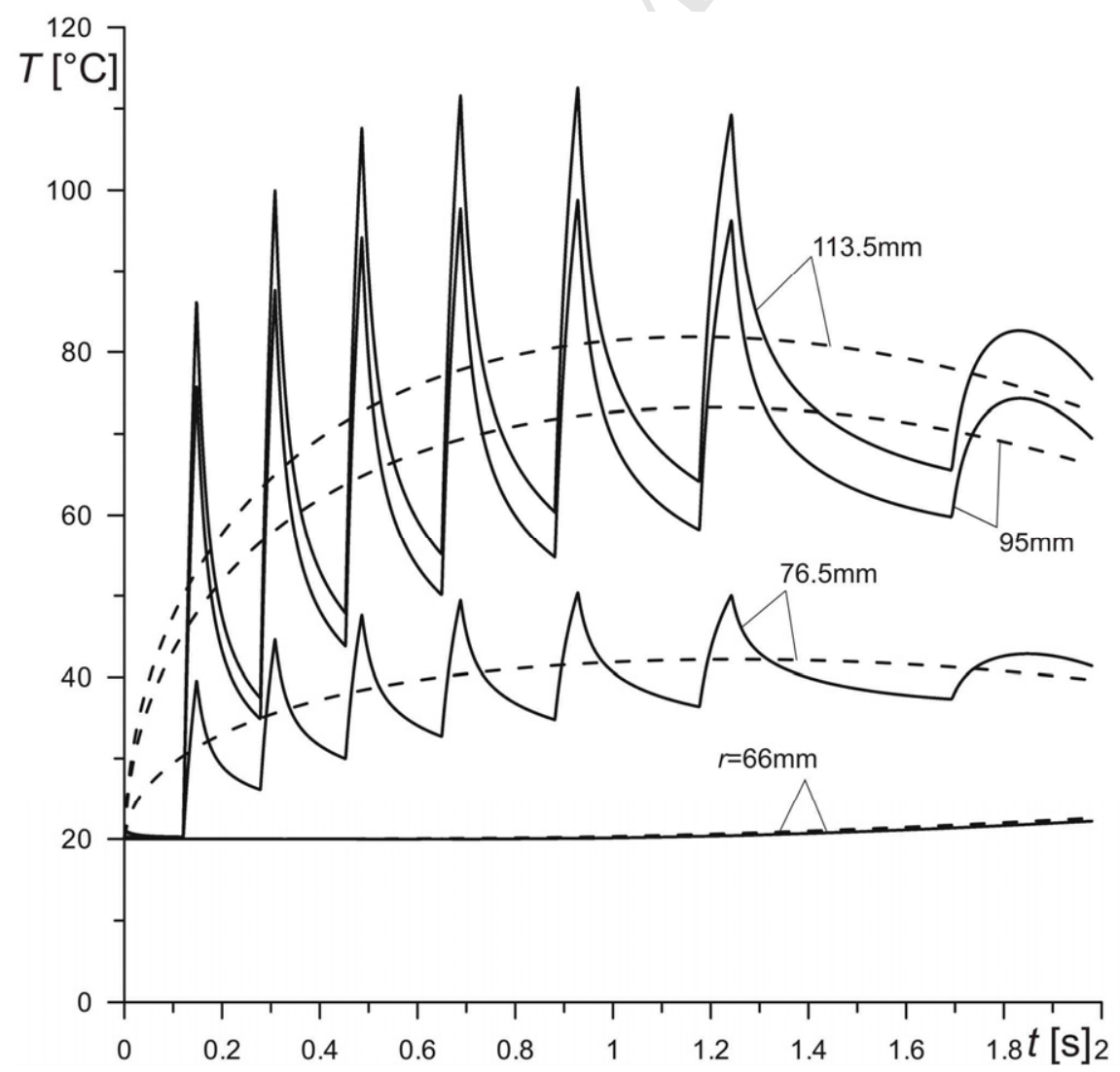

Fig. 4 


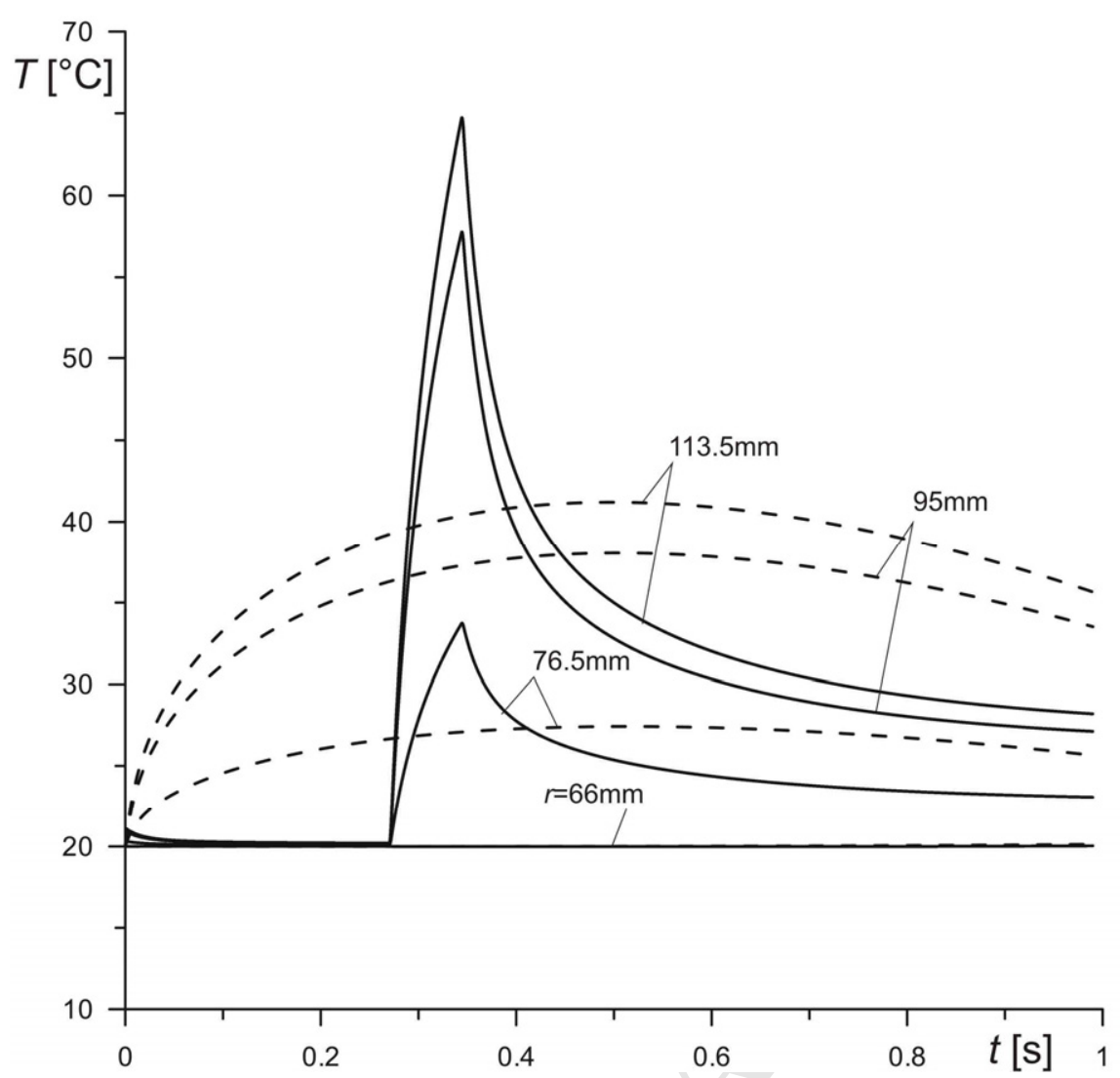

Fig. 5 


\section{ACCEPTED MANUSCRIPT}
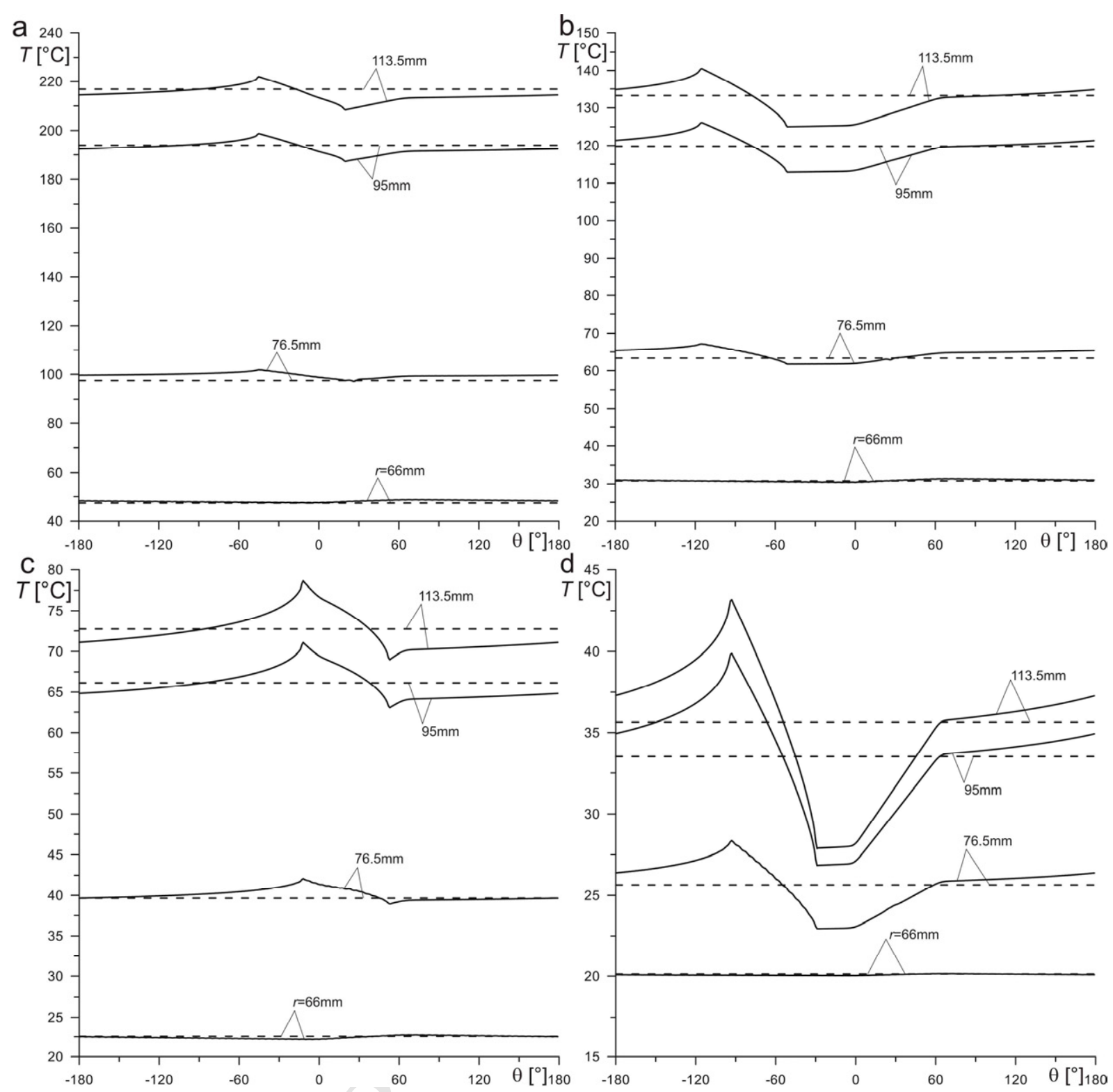

Fig. 6 

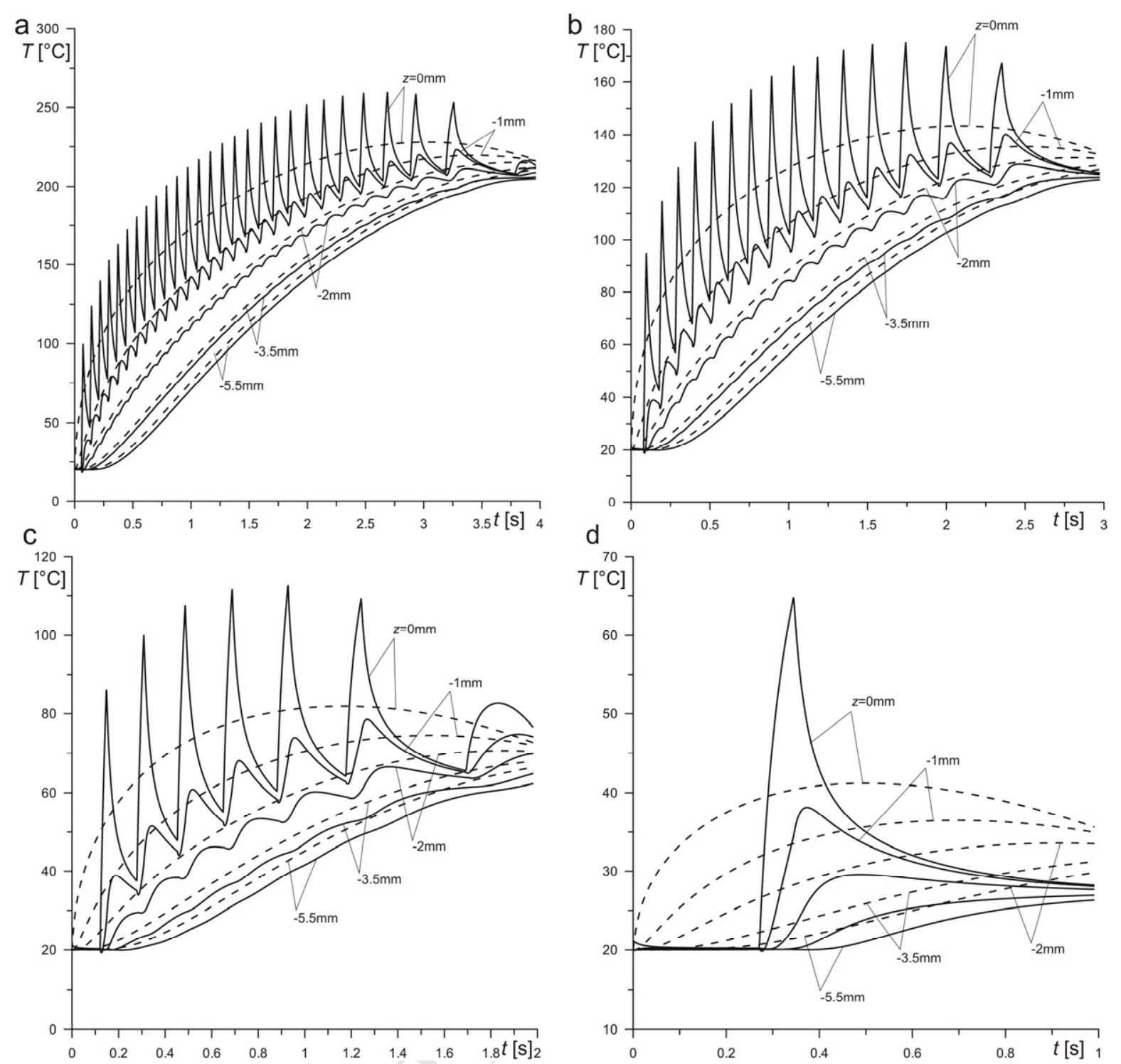

Fig. 7 


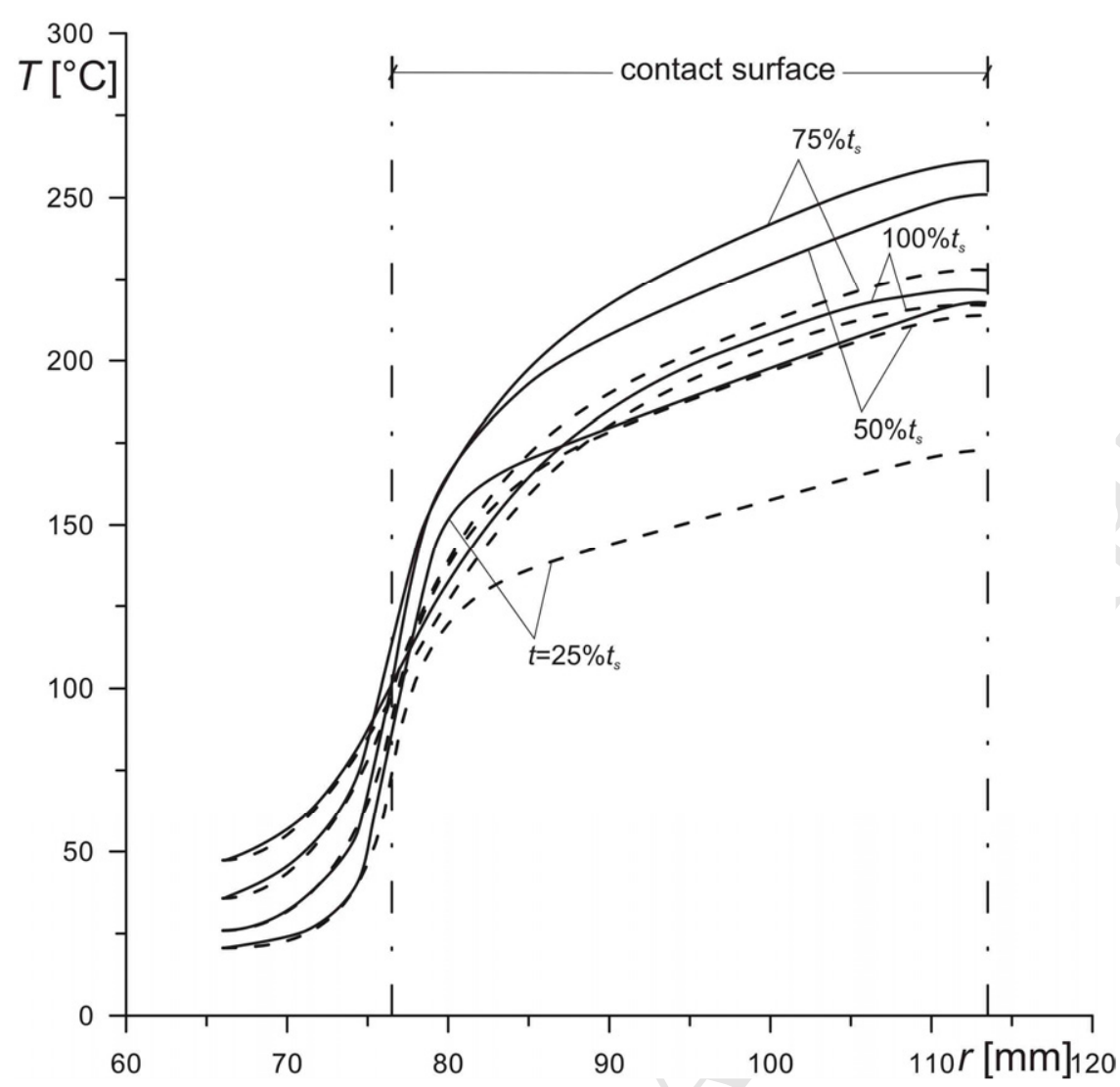

Fig. 8

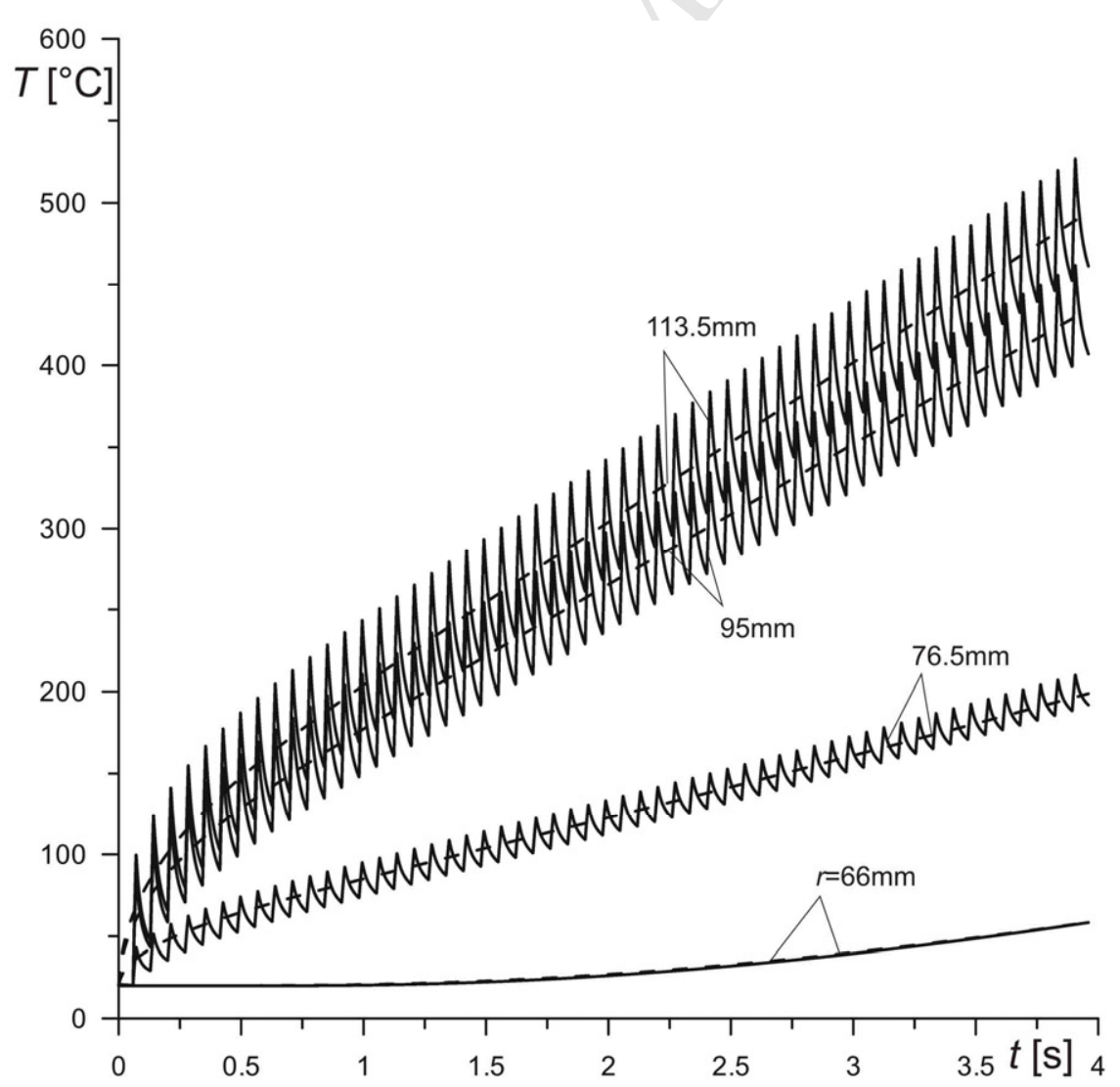

Fig. 9 


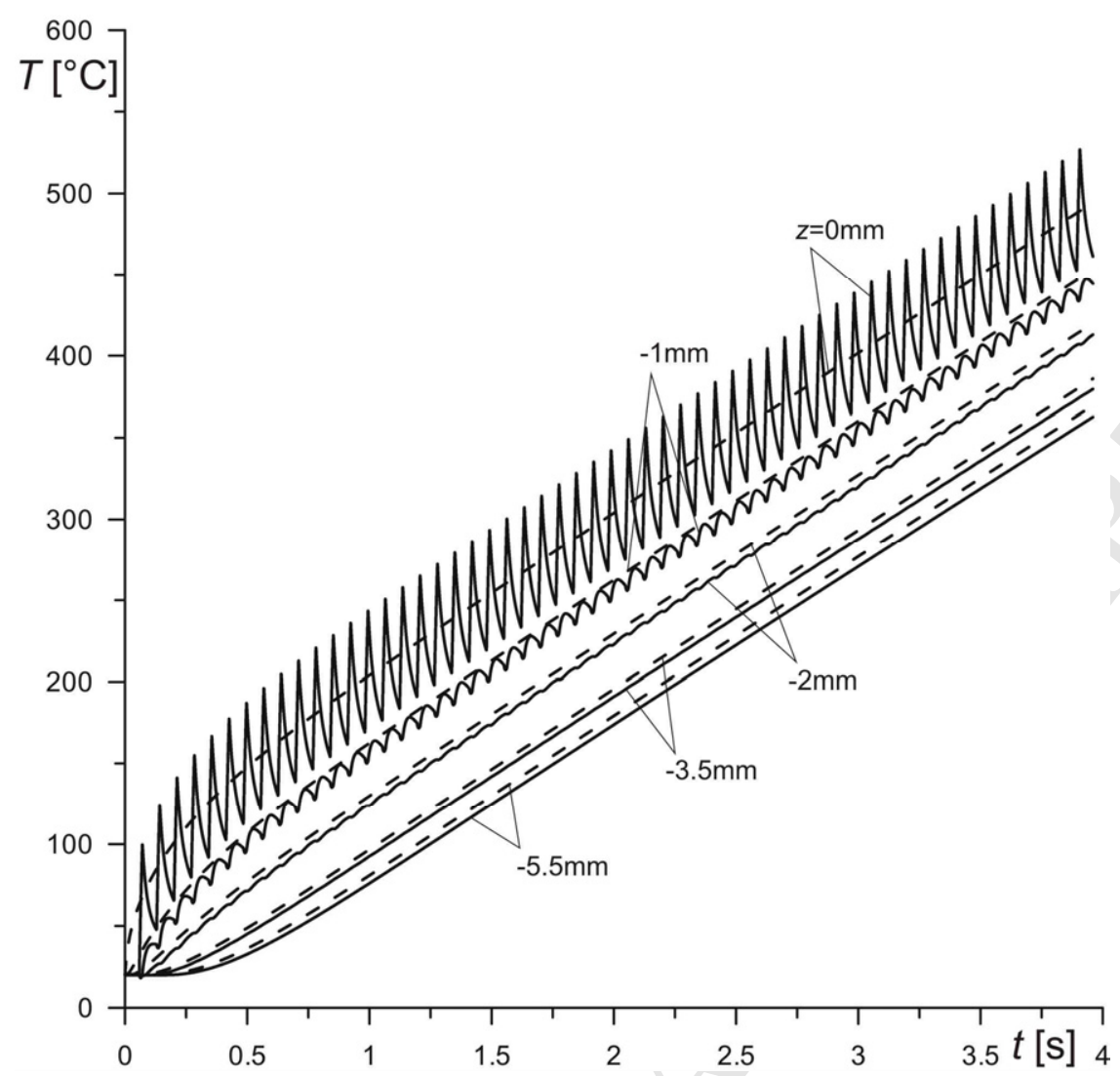

Fig. 10

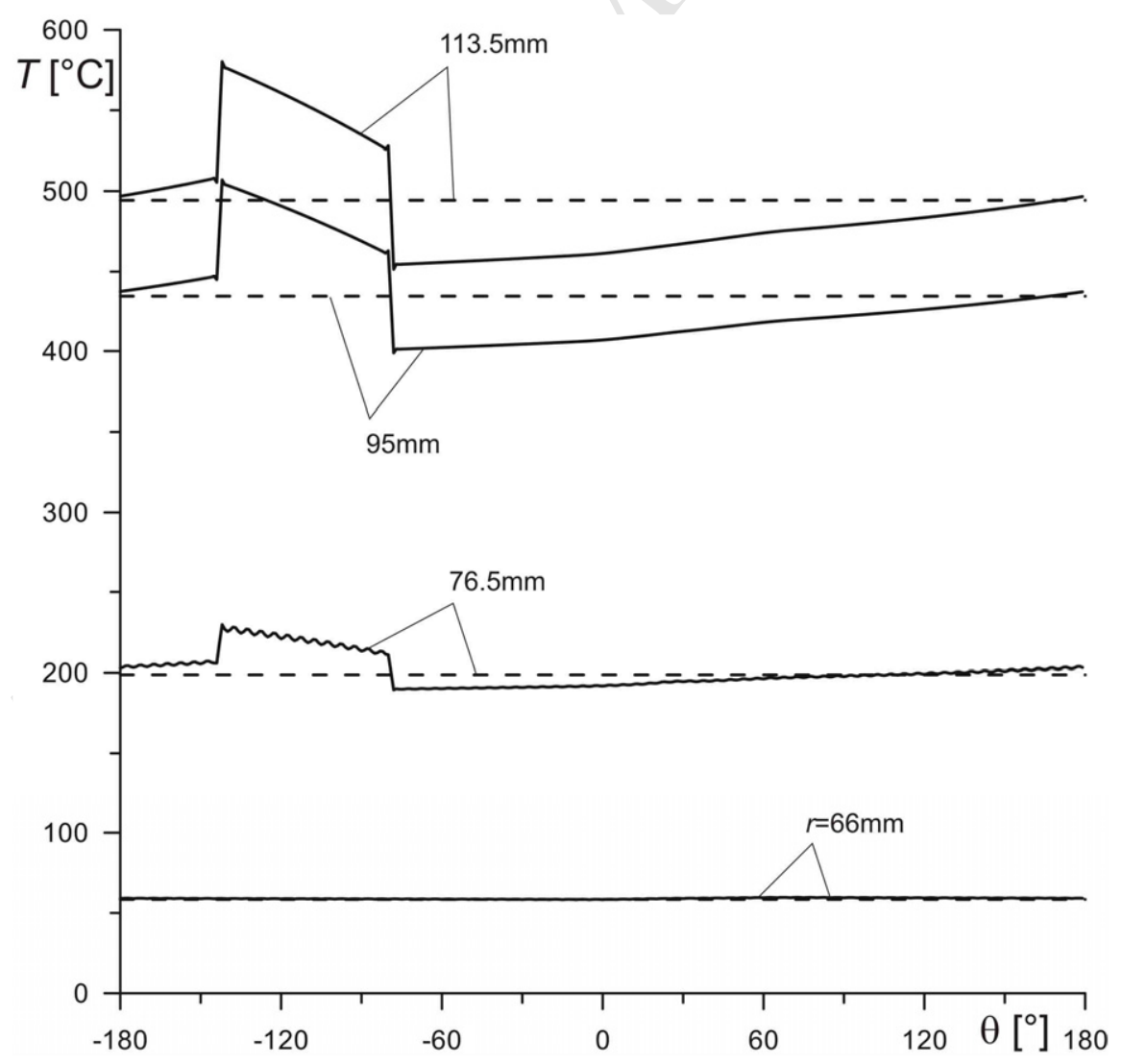

Fig. 11 


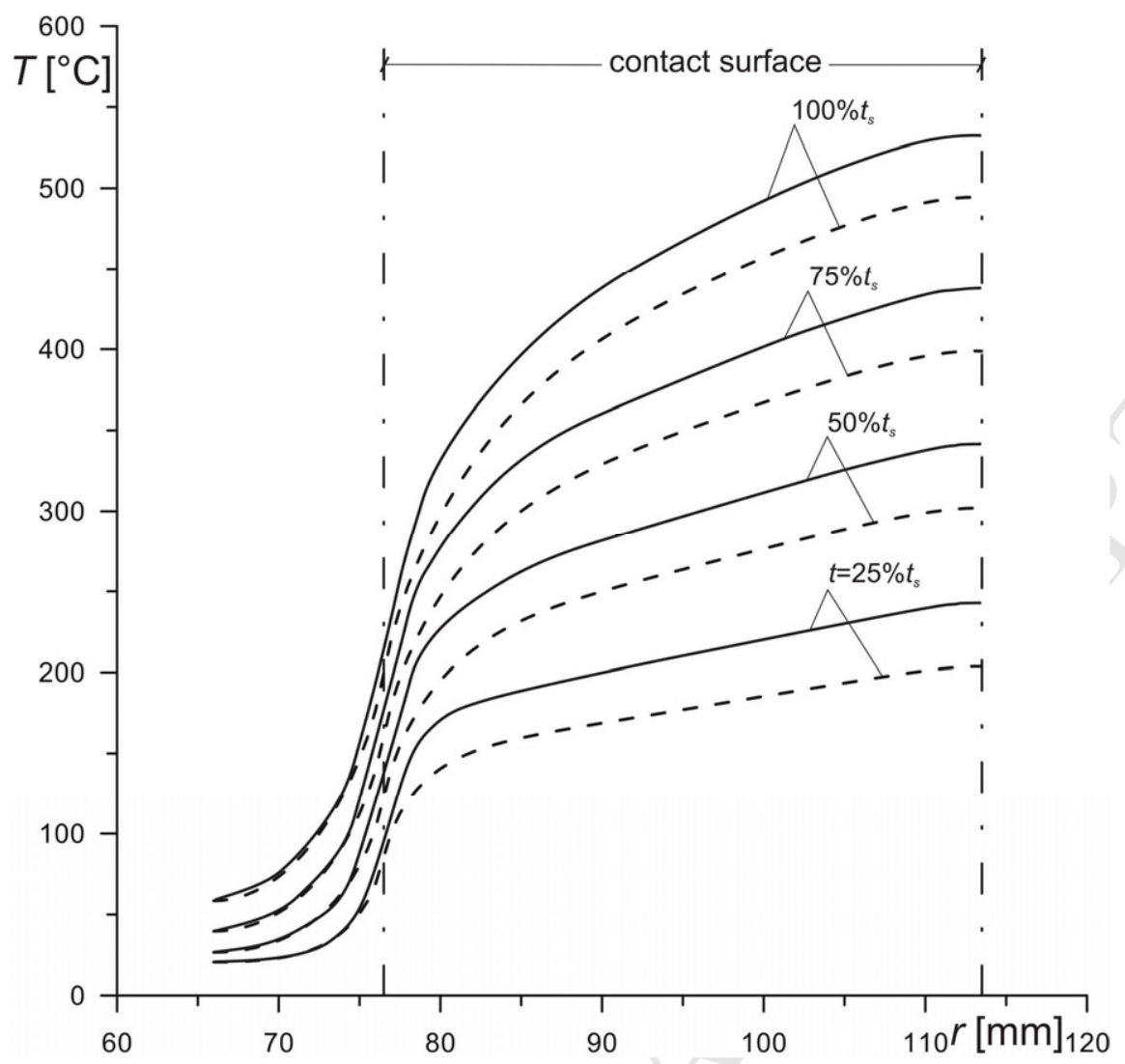

Fig. 12

\begin{tabular}{|c|c|c|c|c|c|}
\hline Items & \multicolumn{4}{|c|}{ Disc } & Pad \\
\hline thermal conductivity, $K[\mathrm{~W} /(\mathrm{mK})]$ & \multicolumn{4}{|c|}{43} & 12 \\
\hline heat capacity, $c[\mathrm{~J} /(\mathrm{kgK})]$ & \multicolumn{4}{|c|}{445} & 900 \\
\hline density, $\rho\left[\mathrm{kg} / \mathrm{m}^{3}\right]$ & \multicolumn{4}{|c|}{7850} & 2500 \\
\hline inner radius, $r[\mathrm{~mm}]$ & & & & & 76.5 \\
\hline outer radius, $R[\mathrm{~mm}]$ & \multicolumn{5}{|c|}{113.5} \\
\hline cover angle of pad, $\phi_{0}$ & \multirow{2}{*}{\multicolumn{4}{|c|}{5.5}} & 64.5 \\
\hline thickness, $\delta[\mathrm{mm}]$ & & & & & 10 \\
\hline radius of the wheel, $R_{w}[\mathrm{~mm}]$ & \multicolumn{5}{|c|}{314} \\
\hline initial velocity of the vehicle, $V_{O}[\mathrm{~km} / \mathrm{h}]$ & 100 & 75 & 50 & 25 & \\
\hline time of braking, $t_{s}[\mathrm{~s}]$ & 3.96 & 2.97 & 1.98 & 0.99 & \\
\hline pressure, $p_{0}[\mathrm{MPa}]$ & \multicolumn{4}{|c|}{3.17} & \\
\hline coefficient of friction, $f$ & \multicolumn{5}{|c|}{0.5} \\
\hline heat transfer coefficient, $h\left[\mathrm{~W} /\left(\mathrm{m}^{2} \mathrm{~K}\right)\right]$ & \multicolumn{5}{|c|}{60} \\
\hline initial temperature, $T_{0}\left[{ }^{\circ} \mathrm{C}\right]$ & \multicolumn{5}{|c|}{20} \\
\hline ambient temperature, $T_{\infty}\left[{ }^{\circ} \mathrm{C}\right]$ & \multicolumn{5}{|c|}{20} \\
\hline
\end{tabular}

Tab. 1. Thermo-physical properties of materials, dimensions and operation conditions for the transient analysis (from Talati and Jalalifar [8]) 